\title{
The use of foresight in technical systems
}

\author{
Sergey Nikitin ${ }^{1, *}$, Arthur Novikov ${ }^{2}$ and Tatyana Novikova ${ }^{2}$ \\ ${ }^{1}$ Voronezh State Technical University, Moscow Avenue, 14, Voronezh, 394026, Russia \\ ${ }^{2}$ Voronezh State University of Forestry and Technologies named after G.F. Morozov, Timiryazeva \\ Str, 8, Voronezh, 394087, Russia
}

\begin{abstract}
The study is intended for engineers designing technical systems. The analytic hierarchy process was used as the main tool of foresight. Nowadays, some experience in the design of technical systems is accumulated. However, in most cases, designers have to sort through all possible factors and parameters of devices. The involvement of experts will reduce the time range of research. The research results show a high Kendall's coefficient of concordance - 0.738. Research materials will allow planning experiments only with the most important factors. This will adjust the protocols for testing new technical systems and significantly reduce costs.
\end{abstract}

\section{Introduction}

Foresight as a tool is used in technological research relatively recently. The basis of foresight is expert methods, which are "the art of giving inaccurate answers to those practical issues that are given even worse answers by other methods [1]". The range of practical issues is infinitely wide, in particular, the authors [2] attempted to "analyze hierarchies" to support decision making in microelectronics and other socio-economic systems. However, the applicability of expert assessments in the simulation of technical systems [3, 4] and the subsequent planning of the experiment proved its feasibility and efficiency. We show the specificity of the applicability of the method of expert assessments in the design of a technical system in the process of separation of forest seeds. Separation of particles with low specific load (seeds, bulk materials with a small grain size, etc.) without sieve is positioned as an alternative to the traditional methods of separation (using sieve, separation, aspiration devices). The variety of technical equipment that implements technology that doesn't use a sieve leads to the need for analytical studies of their operational parameters [4].

This technology can be used in the primary processing of reproductive material in forestry and agriculture, but it does not fully comply with modern principles of nondestructive quality control $[5,6]$. The aim of the study is to identify the applicability of one of the foresight techniques for optimizing the design of a technical system presented in the form of a separator without sieve.

\footnotetext{
*Corresponding author: niksal76@mail.ru
} 


\section{Materials and Methods}

As the main method of foresight, the Saaty's analytic hierarchy process [7] was used. In the analysis of hierarchies, Kendall's coefficient of concordance W [8] was used as an indicator of consensus. Its use is advisable in research on transport [9], in agriculture and forestry [10], information systems and many other areas when assessing the degree of expediency of the use of certain factors in the design of a technical system. First, the coefficient of concordance was calculated for the entire set of experts. Then one of the experts was excluded and the coefficient of concordance was calculated again for the remaining ones. Subsequently, the above procedures were carried out for all other expert assessments. In order to keep the unity of opinions, the hierarchies of that expert were excluded, with the exclusion of which the maximum increase in concordance was observed.

An average prior rank diagram of the distribution of factors reflecting the collective opinion of experts was built, and the significance of each factor was assessed. Here, the factors were plotted on the abscissa axis in descending order of their rank, and on the ordinate axis - the sum of ranks for the corresponding factor.

\section{Results}

Separation of particles with low specific load (seeds, bulk materials with a small grain size, etc.) without the sieve is positioned as an alternative to the traditional methods of separation (using sieve, separation, aspiration devices). The variety of technical equipment that implements technology that doesn't use the sieve leads to the need for analytical studies of their operational parameters. It is often necessary to analyze a fairly large number of factors and parameters, which, when studying technical systems, especially in interaction with biological objects in the form of forest reproductive material, can lead to a huge number of experiments exceeding a thousand experiments.

Therefore, taking into account the specifics of research, it is necessary to use foresight, attracting experts from among scientists in the field of mechanization of forestry and agriculture, as well as develop questionnaires for the most complete and reliable analysis of factors. In the study of the technological process of the technical system using the example of a disk type separator, 11 factors were identified (Fig. 1). Using a table of random numbers, they were arranged randomly in questionnaires. The factors were ranked by the scientists competent in this matter.

Next, the authors processed questionnaires received from 10 experts. Table 1 illustrates the use of the rank matrix for expert analysis of a technical system.

With its help, the coefficient of concordance $W$, which is an estimate of the degree of consistency of opinions of researchers covered by the question, was calculated by the formula

$$
W=\frac{S}{1 / 12 m^{2}\left(n^{3}-n\right)-\sum_{j=1}^{m} T_{i}}
$$

where $S$ - the sum of squared deviations;

$m$ - the number of interviewed experts, $m=10$;

$n$ - the number of factors, $n=11$;

$T_{i}=\frac{1}{12} \sum_{j=1}^{m}\left(t_{j}^{3}-t_{j}\right)$

, where $t_{j}$ - the $j$-th number of identical ranks in the $j$-th ranking.

The sum of the squared deviations was calculated by the formula 


$$
S=\sum_{i=1}^{m}\left(\sum_{j=1}^{m} a_{i j}-L\right)^{2}
$$

where $a_{i j}$ - rank (order number in the survey) of $i$-th factor of the $j$-th specialist

$$
L \text { - average value of the sum of ranks for each factor } L=\frac{\sum_{j=1}^{n} \sum_{j=1}^{m} a_{i j}}{n} \text {. }
$$

\begin{tabular}{|c|c|}
\hline 1 & - Rotation frequency of the cylinder working parts \\
\hline 2 & $\begin{array}{l}\text { - Angle of inclination of the cylinder working parts to } \\
\text { the horizon }\end{array}$ \\
\hline 3 & $\begin{array}{l}\text { - Angle of slope of the Board to the surface of the } \\
\text { cylinder }\end{array}$ \\
\hline 4 & - Disk diameter of the cylinder of the working body \\
\hline 5 & $\begin{array}{l}\text { - Angle of inclination of the sloped boards to the } \\
\text { horizon }\end{array}$ \\
\hline 6 & - Working parts length \\
\hline 7 & - Submission of material to the working parts \\
\hline 8 & - Width of the sorting groove of the cylinder \\
\hline 9 & - Thickness of the disc cylinder working parts \\
\hline 10 & - Form a sloped Board \\
\hline & $\begin{array}{l}\text { - Place of sloped Board installation in relation to the } \\
\text { cylinder }\end{array}$ \\
\hline
\end{tabular}

\begin{tabular}{|c|c|c|c|c|c|c|c|c|c|c|c|}
\hline & $\mathrm{x}_{1}$ & $\mathrm{X}_{2}$ & $\mathrm{x}_{3}$ & $\mathrm{X}_{4}$ & $\mathrm{x}_{5}$ & $x_{6}$ & $\mathrm{x}_{7}$ & $\mathrm{X}_{8}$ & $\mathrm{X}_{9}$ & $\mathrm{x}_{10}$ & $\mathrm{x}_{11}$ \\
\hline 1 & 2 & 1 & 4 & 6 & 9 & 3 & 5 & 11 & 10 & 8 & 7 \\
\hline 2 & 1 & 2 & 3 & 5 & 4 & 7 & 9 & 10 & 6 & 11 & 8 \\
\hline 3 & 1 & 2 & 3 & 6 & 5 & 4 & 7 & 8 & 9 & 10 & 11 \\
\hline 4 & 3 & 1 & 2 & 8 & 6 & 4 & 7 & 9 & 5 & 11 & 10 \\
\hline 5 & 2 & 3 & 1 & 4 & 5 & 6 & 7 & 8 & 9 & 10 & 11 \\
\hline 6 & 1 & 2 & 3 & 4 & 6 & 5 & 7 & 8 & 11 & 9 & 10 \\
\hline 7 & 2 & 1 & 3 & 4 & 5 & 8 & 7 & 6 & 10 & 9 & 11 \\
\hline 8 & 1 & 2 & 2 & 2 & 3 & 2 & 1 & 3 & 4 & 4 & 5 \\
\hline 9 & 2 & 1 & 3 & 5 & 4 & 7 & 6 & 8 & 9 & 10 & 11 \\
\hline 10 & 1 & 2 & 3 & 4 & 5 & 6 & 7 & 9 & 8 & 11 & 10 \\
\hline$\sum_{j=1}^{m} a_{i j}$ & 16 & 17 & 27 & 48 & 52 & 52 & 63 & 80 & 81 & 93 & 94 \\
\hline$\Delta_{i}=\sum_{j=1}^{m} a_{i j}-L$ & -41 & -40 & -30 & -9 & -5 & -5 & 6 & 23 & 24 & 36 & 37 \\
\hline$\Delta_{i}^{2}$ & 1651 & 1571 & 878 & 75 & 21 & 21 & 40 & 546 & 594 & 1322 & 1396 \\
\hline \multicolumn{12}{|c|}{$\mathrm{T}_{\mathrm{i}}=10,5$} \\
\hline
\end{tabular}

Fig. 1. The main factors affecting the operating process of a technical system.

Table 1. Matrix of rank correlation of expert analysis of a technical system (data from [10]). 
After calculating the Kendall's coefficient of concordance W, its significance was determined by criterion $\chi^{2}$, comparing its calculated and tabular values, since the value $m(n$ - 1) W has $\chi^{2}$-distribution with the number of degrees of freedom $f=n-1$.

The calculated value of the $\chi^{2}$-distribution was determined by the formula

$$
\chi^{2}=\frac{S}{1 / 12 m n(n+1)-\frac{1}{n-1} \sum_{j=1}^{m} T_{i}}
$$

In our case, $\chi_{\text {calc }}^{2}=74.5$. From statistical tables, we find that for a $5 \%$ level of significance with $\mathrm{f}=11-1=10$ degrees of freedom, the value of $\chi^{2}$ calc $=18.307$. Since the value of $\chi^{2}$-distribution calculated by the formula (3) is larger than tabular one with an appropriate number of degrees of freedom, we are $95 \%$ likely to say that expert opinion on the degree of influence of factors is assessed by the coefficient of concordance $\mathrm{W}=0.738$ and the consistency of scientists is not random.

Fig. 2 shows the average prior diagram of the ranks of the distribution of factors, reflecting the collective opinion of experts on the hierarchy of factors affecting the performance of the technical system.

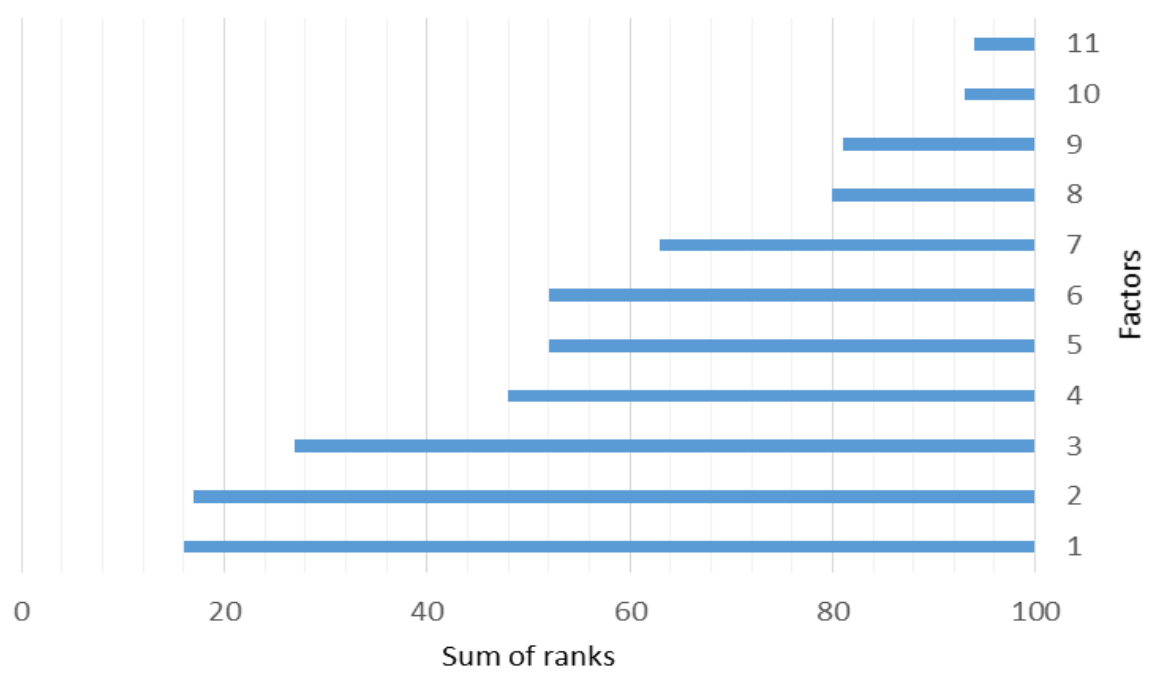

Fig. 2. Average prior rank diagram.

Based on prior ranking, taking into account the results of the conducted psychological experiment, 3 factors $\left(\mathrm{x}_{1}, \mathrm{x}_{2}, \mathrm{x}_{3}\right)$ were selected for further simulation - the rotational speed of the cylinder of the working body, the angle of inclination of the cylinder of the working body to the horizon, the angle of inclination of the sloped board to the surface of the cylinder - assuming that they most strongly influence the quantitative and qualitative indicators of the efficiency of cleaning seeds from hard-separable impurities.

\section{Discussions}

Definitely, foresight with the study of the opinions of scientists in the form of brainstorming and expert analysis helps in making decisions about the feasibility of choosing direction in the design of technical systems. However, it is not always possible to find a sufficiently large number of experts in this area due to its limited distribution. In this case, it is necessary to answer the question about the optimal number of experts and refer 
them only to a narrow circle of specialists of the required area, or the possible questionnaire among specialists with technical education. To this end, it is necessary to plan research with the involvement of a wide range of experts. However, even with a small number of experts, using the analytic hierarchy process yields a rather high coefficient of concordance -0.738 (the maximum value is 1.0 ).

\section{Conclusion}

Using the analytic hierarchy process when designing technical systems a priori will allow:

- reducing the time range when planning a technical experiment;

- planning experiments only with the most important factors from the point of view of competent experts;

- compensating part of the costs of enumeration of all possible options for conducting experiments.

\section{References}

1. P. Legendre, J. Agric. Biol. Environ. Stat., 10, 226-245 (2005).

2. T. Novikova, Microelectronics design center project management system (Voronezh, Voronezh State University of Forestry and Technologies named after G.F. Morozov, 2014)

3. A. Spickermann, V. Grienitz, H. von der Gracht, Technol. Forecast. Soc. Change 89, 201-221 (2014)

4. A. Novikov, Substantiation of the technological scheme, design and parameters of the disk separator of forest seeds, PhD Thesis (Voronezh State University of Forestry and Technologies named after G.F. Morozov, 2002)

5. M. Farhadi, M. Tigabu, P. Odén, Silva Fenn. 49, 1340 (2015)

6. A. Rahman, B. Cho, Seed Sci. Res. 26, 285-305 (2016)

7. T. Saaty, Decis. Sci. 18, 157-77 (1987)

8. M. Marozzi, J. Stat. Comput. Simul. 84, 1843-1850 (2014)

9. V. Podvezko, H. Sivilevičius, Transport 28, 389-403 (2013)

10. M. Shibata, Ecology 83, 1727 (2002) 